\title{
Sex Steroid Hormone
} Single-Nucleotide Polymorphisms, Pesticide Use, and the Risk of Prostate Cancer: A Nested Case-Control Study within the Agricultural Health Study

\author{
Carol H. Christensen ${ }^{1}$, Kathryn Hughes Barry 2,3,4, Gabriella Andreotti2, \\ Michael C. R. Alavanja ${ }^{2}$, Michael B. Cook ${ }^{5}$, Scott P. Kelly ${ }^{5}$, Laurie A. Burdett ${ }^{6}$, \\ Meredith Yeager ${ }^{6}$, Laura E. Beane Freeman ${ }^{2}$, Sonja I. Berndt ${ }^{2}$ and Stella Koutros ${ }^{2 *}$ \\ 1 Office of Science, Center for Tobacco Products, Food and Drug Administration, Document Control Center, Silver Spring, \\ MD, USA, ${ }^{2}$ Occupational and Environmental Epidemiology Branch, Department of Health and Human Services, Division \\ of Cancer Epidemiology and Genetics, National Cancer Institute, National Institutes of Health, Rockville, MD, USA, \\ ${ }^{3}$ Department of Epidemiology and Public Health, University of Maryland School of Medicine, Baltimore, MD, USA, \\ ${ }^{4}$ Program in Oncology, University of Maryland Marlene and Stewart Greenebaum Comprehensive Cancer Center, \\ Baltimore, MD, USA, ${ }^{5}$ Metabolic Epidemiology Branch, Department of Health and Human Services, Division of Cancer \\ Epidemiology and Genetics, National Cancer Institute, National Institutes of Health, Rockville, MD, USA, ${ }^{6}$ Cancer \\ Genomics Research Laboratory, Frederick National Laboratory for Cancer Research, Leidos Biomedical Research Inc., \\ National Cancer Institute-Frederick, Frederick, MD, USA
}

OPEN ACCESS

Edited by:

Imtiaz Ahmad Siddiqui,

University of

Wisconsin-Madison, USA

Reviewed by:

Amit D. Raval,

Healthcore Inc., USA

Lital Keinan-Boker,

University of Haifa, Israel

*Correspondence:

Stella Koutros

koutross@mail.nih.gov

Specialty section:

This article was submitted

to Cancer Epidemiology

and Prevention,

a section of the journal

Frontiers in Oncology

Received: 19 July 2016 Accepted: 25 October 2016 Published: 21 November 2016

Citation:

Christensen $\mathrm{CH}$, Barry $\mathrm{KH}$,

Andreotti G, Alavanja MCR, Cook MB, Kelly SP, Burdett LA,

Yeager $M$, Beane Freeman $L E$,

Berndt SI and Koutros S

(2016) Sex Steroid Hormone Single-Nucleotide Polymorphisms,

Pesticide Use, and the

Risk of Prostate Cancer:

A Nested Case-Control Study within the Agricultural Health Study.

Front. Oncol. 6:237.

doi: 10.3389/fonc.2016.00237
Experimental and epidemiologic investigations suggest that certain pesticides may alter sex steroid hormone synthesis, metabolism or regulation, and the risk of hormone-related cancers. Here, we evaluated whether single-nucleotide polymorphisms (SNPs) involved in hormone homeostasis alter the effect of pesticide exposure on prostate cancer risk. We evaluated pesticide-SNP interactions between 39 pesticides and SNPs with respect to prostate cancer among 776 cases and 1,444 controls nested in the Agricultural Health Study cohort. In these interactions, we included candidate SNPs involved in hormone synthesis, metabolism or regulation ( $N=1,100)$, as well as SNPs associated with circulating sex steroid concentrations, as identified by genome-wide association studies $(N=17)$. Unconditional logistic regression was used to estimate odds ratios (ORs) and 95\% confidence intervals (Cls). Multiplicative SNP-pesticide interactions were calculated using a likelihood ratio test. We translated $p$-values for interaction into $q$-values, which reflected the false discovery rate, to account for multiple comparisons. We observed a significant interaction, which was robust to multiple comparison testing, between the herbicide dicamba and rs8192166 in the testosterone metabolizing gene SRD5A1 (p-interaction $=4.0 \times 10^{-5} ; q$-value $\left.=0.03\right)$, such that men with two copies of the wild-type genotype $\mathrm{CC}$ had a reduced risk of prostate cancer associated with low use of dicamba $(\mathrm{OR}=0.6295 \% \mathrm{Cl}: 0.41,0.93)$ and high use of dicamba $(\mathrm{OR}=0.44,95 \% \mathrm{Cl}$ : $0.29,0.68)$, compared to those who reported no use of dicamba; in contrast, there was

Abbreviations: AHS, Agricultural Health Study; CI, confidence interval; FDR, false discovery rate; OR, odds ratio, PNCC, prostate nested case-control study; SNP, single-nucleotide polymorphism. 
no significant association between dicamba and prostate cancer among those carrying one or two copies of the variant T allele at rs8192166. In addition, interactions between two organophosphate insecticides and SNPs related to estradiol metabolism were observed to result in an increased risk of prostate cancer. While replication is needed, these data suggest both agonistic and antagonistic effects on circulating hormones, due to the combination of exposure to pesticides and genetic susceptibility, may impact prostate cancer risk.

Keywords: prostate cancer, pesticides, sex steroid hormones, single-nucleotide polymorphism, interaction

\section{INTRODUCTION}

Farmers have a greater risk of prostate cancer than the general population or other occupational groups (1-3). Investigations within the Agricultural Health Study (AHS), a large prospective cohort of pesticide applicators, have identified links between prostate cancer, including aggressive forms of the disease, and pesticide exposure (4). Previous studies within the AHS have suggested that pesticides may interact with single-nucleotide polymorphisms (SNPs) along several different biological pathways to influence the risk of prostate cancer (5-9); however, additional biological pathways, including those involving hormones, have yet to be examined.

Prostate cancer has long been thought to be a hormonally modulated disease (10-12). Experimental and epidemiologic investigations suggest that certain pesticides may alter sex steroid hormone synthesis, metabolism and regulation, and thereby may interfere with sex steroid hormone homeostasis and alter risk of hormone-related cancers (13-18). Therefore, it is possible that variants in genes along this pathway may alter or amplify pesticide effects on hormone homeostasis and alter prostate cancer disease risk.

In the present hypothesis-generating study, we investigated genetic variation along the sex steroid hormone candidate pathway, as well as SNPs that have been associated with circulating sex steroid concentrations in genome-wide association studies (GWAS) as potential modifying factors of the relationship between pesticide exposure and prostate cancer risk.

\section{MATERIALS AND METHODS}

\section{Study Population and Genotyping}

Criteria for selection into this case-control study have been described elsewhere (9). Briefly, this case-control study is nested within the AHS cohort, a prospective study that includes private and commercial pesticide applicators in Iowa and North Carolina (19). Cases were white male AHS pesticide applicators that were cancer free at enrollment, provided a buccal cell sample, and diagnosed with prostate cancer between enrollment (1993-1997) and 2004. Cancer incidence information, as well as tumor characteristics (Gleason score, stage) for the characterization of aggressive prostate cancer in the AHS (4), was obtained by linkage to cancer registry files in Iowa and North Carolina. Controls were white male AHS pesticide applicators frequency matched 2:1 to cases by age ( \pm 1 year). DNA was extracted from buccal cells using the Autopure protocol (Qiagen Inc., Valencia, CA, USA) at NCI's Cancer Genomics Research Laboratory, where the genotyping was also performed. Genotyping analysis was conducted using the Custom Infinium ${ }^{\circledR}$ BeadChip Assays (iSelect ${ }^{\mathrm{TM}}$ ) from Illumina Inc. and has been described elsewhere in detail (9). Exclusions due to quality control (insufficient/poor DNA quality or $<90 \%$ completion rate for genotyping assays) or a genetic background that was inconsistent with European ancestry resulted in the final sample size of 776 cases and 1,444 controls. Study protocols were reviewed and approved by all relevant Institutional Review Boards.

\section{Exposure Information}

Lifetime use of 50 specific pesticides was collected via self-administered questionnaires at enrollment in the AHS. Information was collected through both an initial enrollment questionnaire (including lifetime use of 22 pesticides) and supplemented with a take-home questionnaire (including lifetime use of an additional 28 pesticides). The take-home questionnaire was completed by 60.4 and $67.2 \%$ of the cases and controls, respectively. In a previous analysis, those who did and those who did not complete the take-home questionnaire were found to share similar characteristics, except for age (20).

Details of pesticide exposure assessment are presented elsewhere (21). The enrollment questionnaires asked participants to report the number of years that they personally applied each specific pesticide ( 1 year or less, $2-5,6-10,11-20,21-30$, or more than 30 years), as well as the number of days per year that they applied that pesticide (less than 5, 5-9, 10-19, 20-39, 40-59, $60-150$, or more than 150 days). The number of years applied was multiplied by the number of days/year to construct a lifetime exposure days exposure metric for each pesticide. In addition, an intensity-weighted metric was calculated for each pesticide by multiplying the total lifetime days by an intensity score [intensity-weighted lifetime exposure days (IWLTED)]. The intensity score was derived from an algorithm based on several factors that may modify pesticide exposure, including mixing status, application method, equipment repair, and use of personal protective equipment $(22,23)$. This metric was subsequently categorized into three groups (none, low, and high IWLTED) for the present analysis using the median cut point of the data to divide low and high, based on the distribution of days among the controls for each of the pesticides included in the analysis. Data were obtained from AHS data release versions P1REL0712.04 and AHSREL201103.00. 
Of the 50 pesticides evaluated at enrollment, we excluded pesticides with less than $10 \%$ prevalence among the controls in the present study due to insufficient numbers for analysis (trichlorfon, ziram, aluminum phosphide, ethylene dibromide, maneb/mancozeb, chlorothalonil, carbon tetrachloride/carbon disulfide, dieldrin, aldicarb, and 2,4,5-trichlorophenoxypropionic acid). We also constructed a single exposure variable for analysis of permethrin by combining information on crop and animal applications, which were asked about separately, leaving 39 pesticides available for analysis.

\section{Gene and SNP Selection}

Genes and SNPs were selected using two approaches. In the first approach, we selected SNPs tagged for candidate genes involved in hormone biosynthesis, regulation, and/or metabolism. We identified hormone-related genes through a search of both the PubMed/Gene database and also the Kyoto Encyclopedia of Genes and Genomes (KEGG) catalog gene search tool using the terms "sex steroid hormone" or "hormone" or "testosterone" or "androgen" or "estrogen" in the keyword search. In addition, we sought information through a search of recent (last 5 years) topical literature reviews or original research studies evaluating the sex steroid hormone pathway to learn of common ways of identifying genes along this pathway (24-27). We excluded SNPs with a minor allele frequency less than $5 \%$ to allow for robust analysis of interactions between genetic loci and pesticide exposures. Following quality control exclusions, there were 1,100 SNPs within 56 hormone-related genes available for analysis.

In the second approach for SNP selection, we selected SNPs that were associated with circulating sex steroid hormone concentrations in GWAS (28-32). To identify these SNPs, we queried the GWAS Catalog ${ }^{1}$ for SNPs that influenced circulating steroid hormone concentration using the terms such as "androgens," "estrogens," "sex hormone-binding globulin (SHBG)," "testosterone," and "estradiol." We identified 17 SNPs at a threshold of $p<10^{-5}$ that were related to circulating hormone levels, ${ }^{2}$ of which 4 were genotyped on the iSelect platform. For the remaining SNPs $(n=13)$, we identified proxies $r^{2} \geq 0.80$ where available using the online tool SNP Annotation and Proxy Search $(\text { SNAP) })^{3}(33)$.

\section{Statistical Analysis}

We used the SAS software (version 9.1; SAS Institute Inc., Cary, NC, USA) to estimate the association between pesticides and prostate cancer and stratified effects by genotype, as well as interaction $p$-values ( $p$-interact), and PLINK (34) to estimate odds ratios (ORs) for SNP main effects. Unconditional logistic regression was used to estimate ORs and 95\% confidence intervals (95\% CIs) for the association between each SNP and the risk of prostate cancer and to estimate the statistical interaction between 39 pesticides and 1,100 steroid hormone pathway SNPs,

${ }^{1}$ http://www.ebi.ac.uk/gwas/home.

${ }^{2}$ http://www.ebi.ac.uk/gwas/docs/about.

${ }^{3}$ https://www.broadinstitute.org/mpg/snap/. as well as 17 SNPs or SNP proxies related to circulating hormone concentrations in GWAS studies, with incident prostate cancer. Genotypes were categorized by the number of variant alleles: 0 , homozygous for wild-type; 1, heterozygous; and 2, homozygous variant. For the SNP main effect analysis, we assumed a logadditive genetic model (model as ordinal variable for number of variant alleles, 0,1 , or 2). For the interaction analysis, we assumed the dominant genetic model (i.e., modeling SNPs in two categories, zero copies of the variant allele, and one or two copies of the variant allele).

We examined the correlation between the 39 pesticides tested; in general, pesticides were not highly correlated with one another (pairwise Spearman correlation coefficients <0.40) (9). All models were adjusted for age (10-year categories) and study state (Iowa, NC, USA); other potential confounding variables, including smoking, body mass index (obesity), physical activity and a family history of prostate cancer, and use of correlated pesticide products, did not change the effect estimate significantly $(<10 \%$ change in OR) and were not retained in the final models. Statistical interactions between pesticides and SNPs were assessed by including a cross-product term and evaluated using the likelihood ratio test, assuming a multiplicative model.

To adjust for the multiple statistical comparisons performed in this analysis, we translated $p$-values for interaction into $q$-values reflecting the false discovery rate (FDR) following the method by Benjamini and Hochberg (35). This method adjusts for the expected proportion of false discoveries as a function of the number of statistical tests performed. We performed FDR analyses by gene to account for the differing numbers of SNPs by gene, such that the number of comparisons for a given gene was 39 (for number of pesticides) multiplied by the number of tag SNPs for the gene. We performed FDR analysis separately for the two groups of selected SNPs, those tagged for sex steroid hormone pathway candidate genes and those that were associated with circulating hormone concentrations in GWAS.

\section{RESULTS}

Population characteristics of the prostate cancer nested casecontrol study have been previously published (5-9) and are also provided in Table 1. Cases and controls were similar with respect to age (matching factor). Prostate cancer cases and the cancer-free control group selected into this nested case-control study did not differ from the larger AHS cohort with respect to state of residence, pesticide applicator type, family history of prostate cancer, or disease characteristics for cases (i.e., stage and grade) $(8,36)$.

The main effects of pesticide exposure on the risk of prostate cancer among nested case-control participants are displayed in Table S1 in Supplementary Material. There were no statistically significant positive associations between pesticides and prostate cancer in the nested case-control set. Evidence of significant positive associations has been observed between fonofos, terbufos, malathion, and aldrin and risk of prostate cancer in the larger cohort analyses (4). Tables $\mathbf{2}$ and $\mathbf{3}$, respectively, list the candidate genes along the hormone synthesis, metabolism, and regulatory pathway included in this study, and also the SNPs identified as 
TABLE 1 | Selected characteristics of the nested case-control study of prostate cancer in the AHS.

\begin{tabular}{|c|c|c|c|c|}
\hline \multirow[b]{2}{*}{ Selected characteristics } & \multicolumn{2}{|c|}{$\begin{array}{c}\text { Controls } \\
(n=1,444)\end{array}$} & \multicolumn{2}{|c|}{$\begin{array}{l}\text { Prostate cancer } \\
\qquad(n=776)\end{array}$} \\
\hline & $n$ & $\%$ & $n$ & $\%$ \\
\hline \multicolumn{5}{|l|}{ Age at enrollment } \\
\hline$<40$ & 5 & 0.4 & 3 & 0.4 \\
\hline $40-49$ & 144 & 10.0 & 74 & 9.5 \\
\hline $50-59$ & 491 & 34.0 & 259 & 33.4 \\
\hline $60-69$ & 634 & 43.9 & 355 & 45.8 \\
\hline$>70$ & 170 & 11.8 & 85 & 11.0 \\
\hline \multicolumn{5}{|l|}{ State of residence } \\
\hline lowa & 991 & 68.6 & 520 & 67.0 \\
\hline North Carolina & 453 & 31.4 & 256 & 33.0 \\
\hline \multicolumn{5}{|l|}{ Applicator type } \\
\hline Private & 1,363 & 94.4 & 741 & 95.5 \\
\hline Commercial & 81 & 5.6 & 35 & 4.5 \\
\hline \multicolumn{5}{|l|}{ First degree family history } \\
\hline No & 1,193 & 82.6 & 575 & 74.1 \\
\hline Yes & 145 & 10.0 & 130 & 16.8 \\
\hline \multicolumn{5}{|l|}{ Prostate cancer stage } \\
\hline I Local & - & - & 578 & 74.5 \\
\hline II Regional & - & - & 156 & 20.1 \\
\hline III Distant & - & - & 12 & 1.5 \\
\hline IV Not staged & - & - & 30 & 3.9 \\
\hline \multicolumn{5}{|l|}{ Prostate cancer grade } \\
\hline Well differentiated & - & - & 38 & 4.9 \\
\hline Moderately differentiated & - & - & 547 & 70.5 \\
\hline Poorly differentiated & - & - & 168 & 21.6 \\
\hline Undifferentiated & - & - & 4 & 0.5 \\
\hline Not graded & - & - & 19 & 2.4 \\
\hline
\end{tabular}

related to circulating hormone concentrations in GWAS and their proxies included in the present study, where applicable. Table S2 in Supplementary Material reports the associations between SNPs tagged for sex steroid hormone pathway genes and risk of prostate cancer.

Tables 4 and 5 present the relation between herbicide and insecticide exposure, respectively, and prostate cancer risk by genotype at certain SNPs tagged for hormone pathway genes or SNPs associated with circulating hormone concentration in GWAS. Gene by pesticide interaction results are presented for associations that met all three of the following criteria: (1) significant interaction between the pesticide and the SNP with prostate cancer (uncorrected $p$ for interaction $<0.01$ ), (2) significant association between the pesticide and prostate cancer $(p<0.05)$ in one genotype stratum with an accompanying monotonic exposure-response pattern, and (3) no association between the pesticide and prostate cancer in the other stratum. Results for statistical interactions that were qualitative in nature (i.e., interactions involving increased risk with exposure in one genotype group and decreased risk in the other) are not presented.

Among men with the homozygous wild-type genotype (CC) at SNP locus rs8192166 in the hormone-associated gene Steroid Reductase 5-alpha-1 (SRD5A1), we observed a reduced risk of prostate cancer among men who reported low use of dicamba $(\mathrm{OR}=0.62,95 \% \mathrm{CI}: 0.41,0.93)$ and high use of dicamba $(\mathrm{OR}=0.44,95 \% \mathrm{CI}: 0.29,0.68)$, as compared to those who
TABLE 2 | Candidate hormonal pathway genes examined for the interaction between 39 pesticides and risk of prostate cancer in the AHS.

Genes in steroid hormone regulation, synthesis, and metabolism (\# of SNPs)

\begin{tabular}{lll}
\hline AKR1C1 (11) & CYP2E1 (21) & SST (9) \\
AKR1C2 (22) & CYP3A4 (6) & STAR (4) \\
AKR1C3 (26) & CYP3A43 (5) & SULF2 (13) \\
AKR1C4 (17) & CYP3A5 (7) & SULT1A1 (3) \\
AKR1D1 (19) & CYP3A7 (1) & SULT1A2 (3) \\
AR (6) & CYP7A1 (12) & SULT1E1 (18) \\
COMT (12) & CYP7B1 (19) & SULT2A1 (13) \\
CYP11A1 (15) & ESR1 (77) & SULT2B1 (24) \\
CYP11B1 (6) & ESR2 (33) & UGT1A (all) (111) \\
CYP11B2 (8) & HSD11B1 (22) & UGT2A3 (6) \\
CYP17A1 (14) & HSD17B1 (4) \\
CYP19A1 (80) & HSD17B2 (51) & UGT2B10 (5) \\
CYP1A1 (5) & HSD17B3 (46) & UGT2B11 (2) \\
CYP1A2 (16) & HSD17B4 (29) & UGT2B4 (18) \\
CYP1B1 (33) & HSD3B1 (6) \\
CYP24A1 (36) & HSD3B2 (14) & \\
CYP27B1 (6) & NCOA3 (11) & \\
CYP2B6 (12) & SHBG (8) & \\
CYP2C9 (15) & SRD5A1 (35) & \\
CYP2D6 (3) & SRD5A2 (23) & \\
\hline
\end{tabular}

reported no use of dicamba (Table 3). In contrast, there was no significant association between dicamba and prostate cancer among those carrying one or two copies of the variant $\mathrm{T}$ allele at $\operatorname{rs} 8192166\left(p\right.$ for interaction $=4.0 \times 10^{-5} ; q$-value $=0.03$ ) (Table 3 ). In addition, the association between dicamba use and prostate cancer was modified by genotype at rs4784336, located in an intronic region of the fat mass and obesity (FTO) gene. Although statistical power was limited, we repeated the same analyses, i.e., the two above listed interactions with dicamba and prostate cancer by genotype, restricting the analysis to more clinically significant subtype of prostate cancer and aggressive prostate cancer cases (distant stage, poorly differentiated grade, Gleason score of $\geq 7$, or fatal prostate cancer), and we observed similar results (Table S3 Supplementary Material). We also reported statistical interactions (uncorrected $p$-interaction $<0.01$ ) between the herbicides butylate, dicamba, and alachlor with SNPs that were associated with circulating hormone concentrations in GWAS or tagged for hormonerelated genes with prostate cancer risk, although these were not robust to correction for multiple statistical comparisons ( $q$-value $>0.05)$ (Table 3 ).

Table 4 presents insecticide associations with prostate cancer risk as modified by SNPs tagged for hormone pathway genes. We observed interactions between the insecticides terbufos, fonofos, malathion, carbaryl, and genetic variation in the estradiol metabolizing gene, $H S B 17 B 4$, although these were not robust to adjustment for multiple comparisons ( $q$-value $>0.05$ ). We did not observe statistically significant interactions or notable exposure-response trends between GWAS identified SNPs and insecticide exposure with prostate cancer. We also did not observe statistically significant interactions or notable exposureresponse trends between fumigants or fungicides exposure and prostate cancer among those with certain measured genotypes (data not shown). 
TABLE 3 | Genome-wide association study (GWAS) SNPs related to circulating level of hormone.

\begin{tabular}{|c|c|c|c|c|c|}
\hline SNP (P if proxy) $)^{a, b}$ & Original SNP $\left(r^{2}\right)$ & Region & Known gene/nearby gene & Reference & $\begin{array}{l}\text { Hormonal relationship identified (GWAS } \\
p \text {-value) }{ }^{c}\end{array}$ \\
\hline rs334698 (P) & rs334699 (1.0) & $1 p 31.3$ & None (nearby NFIA) & $(37)$ & Testosterone $\left(1.0 \times 10^{-41}\right)$ \\
\hline rs334703 (P) & rs334699 (1.0) & $1 \mathrm{p} 31.3$ & None (nearby NFIA) & $(37)$ & SHBG $\left(2.0 \times 10^{-21}\right)$ \\
\hline rs1260326 (P) & rs780093 (0.90) & 2p23.3 & $\begin{array}{l}\text { None (nearby FNDC4, LOC729823, } \\
\text { GCKR, and IFT172) }\end{array}$ & (28) & SHBG $\left(9.0 \times 10^{-6}\right)$ \\
\hline rs6900902 (P) & rs9322817 (1.0) & $6 q 16.3$ & HACE1 & (38) & Testosterone $\left(6.0 \times 10^{-8}\right)$ \\
\hline rs9332222 (P) & rs2185570 (1.0) & 10q23.33 & CYP2C9 & (32) & SHBG $\left(9.0 \times 10^{-6}\right)$ \\
\hline rs4149056 & $\mathrm{n} / \mathrm{a}$ & 12p12.1 & SLC01B1 & $(28)$ & SHBG $\left(2.0 \times 10^{-08}\right)$ \\
\hline rs727479 & $\mathrm{n} / \mathrm{a}$ & $15 q 21.2$ & CYP19A1 & (31) & Estradiol $\left(3.3 \times 10^{-7}\right)$ \\
\hline rs4784336 (P) & rs12596210 (0.93) & $16 q 12$ & FTO & (31) & SHBG $\left(9.0 \times 10^{-6}\right)$ \\
\hline rs12600130 (P) & rs12596210 (0.85) & $16 q 12.2$ & FTO & (31) & Testosterone $\left(6.0 \times 10^{-8}\right)$ \\
\hline rs1799941 (P) & rs12150660 (0.96) & 17p13.1 & SHBG & $(30,28)$ & SHBG $\left(2.0 \times 10^{-106}\right) /$ testosterone levels $\left(1 \times 10^{-41}\right)$ \\
\hline rs1641536 (P) & rs1641537 (0.85) & 17p13.1 & SHBG & $(28)$ & SHBG $\left(2.0 \times 10^{-16}\right)$ \\
\hline rs11552708 (P) & rs72829446 (0.93) & 17p13.1 & TNFSF13 and EIF4A1 & (29) & DHT $\left(9 \times 10^{-10}\right)$ \\
\hline rs6259 (P) & rs72829446 (0.93) & $17 \mathrm{p} 13.1$ & SHBG & (29) & $\mathrm{DHT}\left(9.0 \times 10^{-10}\right)$ \\
\hline rs2909430 (P) & rs1625895 (1.0) & $17 p 13.1$ & TP53/reported gene SHBG & (28) & SHBG $\left(2 \times 10^{-21}\right)$ \\
\hline rs9901675 & $\mathrm{n} / \mathrm{a}$ & 17p13.1 & EIF4A1 & $(28)$ & SHBG $\left(1.5 \times 10^{-07}\right)$ \\
\hline rs727428 & $\mathrm{n} / \mathrm{a}$ & $17 p 13.1$ & SHBG & (31) & SHBG $\left(2.1 \times 10^{-16}\right)$ \\
\hline rs1017993 (P) & rs2637125 (0.92) & $19 q 13$ & SULT2A1 & (32) & DHEAS $\left(2.6 \times 10^{-19}\right)$ \\
\hline
\end{tabular}

aSNP Annotation and Proxy Search (SNAP) ( $r^{2}>0.80$, CEU, 1,000 genome project, all defaults) (April 2014: https://www.broadinstitute.org/mpg/snap/ldsearch.php).

bStatistical significance (SNP-trait p-value $<1.0 \times 10^{-5}$ ) in the overall (initial GWAS + replication) population (http://Www.genome.gov/27529028).

'GWAS p-value (http://www.genome.gov/gwastudies/index.cfm?pageid=26525384\#searchForm).

SHBG, sex hormone-binding globulin; DHT, dihydrotestosterone; DHEAS, dehydroepiandrosterone.

TABLE 4 | Interactions between herbicides and SNPs with prostate cancer risk $(p<0.01)$.

\begin{tabular}{|c|c|c|c|c|c|c|c|c|c|c|c|}
\hline \multirow{2}{*}{$\begin{array}{l}\text { Exposure } \\
\text { SNP }\end{array}$} & & \multirow[b]{2}{*}{ Pesticide } & \multirow[b]{2}{*}{ Genotype } & \multicolumn{2}{|c|}{ None } & \multicolumn{2}{|c|}{ Low exposure } & \multicolumn{2}{|c|}{ High exposure } & \multirow[b]{2}{*}{$p$-int ${ }^{a}$} & \multirow[b]{2}{*}{$q$-value ${ }^{b}$} \\
\hline & & & & $\mathrm{Ca} / \mathrm{Co}$ & REF & $\mathrm{Ca} / \mathrm{Co}$ & OR (95\% CI) & $\mathrm{Ca} / \mathrm{Co}$ & OR (95\% Cl) & & \\
\hline $\begin{array}{l}\text { Hormonal } \\
\text { pathway }\end{array}$ & Gene & & & & & & & & & & \\
\hline rs8192166 & SRD5A1 & Dicamba & $\begin{array}{c}\mathrm{CC} \\
\mathrm{CT}+\mathrm{TT}\end{array}$ & $\begin{array}{l}133 / 173 \\
189 / 396\end{array}$ & $\begin{array}{l}1.0 \\
1.0\end{array}$ & $\begin{array}{c}64 / 131 \\
108 / 229\end{array}$ & $\begin{array}{l}0.62(0.41,0.93) \\
0.95(0.69,1.30)\end{array}$ & $\begin{array}{c}49 / 142 \\
127 / 218\end{array}$ & $\begin{array}{l}0.44(0.29,0.68) \\
1.15(0.85,1.57)\end{array}$ & $4.0 \times 10^{-5}$ & 0.03 \\
\hline rs3798577 & ESR1 & Butylate & $\begin{array}{c}T \\
\mathrm{CT}+\mathrm{CC}\end{array}$ & $\begin{array}{l}162 / 256 \\
338 / 647\end{array}$ & $\begin{array}{l}1.0 \\
1.0\end{array}$ & $\begin{array}{c}10 / 42 \\
42 / 110\end{array}$ & $\begin{array}{l}0.40(0.19,0.83) \\
0.74(0.50,1.08)\end{array}$ & $\begin{array}{c}8 / 42 \\
64 / 97\end{array}$ & $\begin{array}{l}0.30(0.14,0.66) \\
1.28(0.90,1.80)\end{array}$ & $8.0 \times 10^{-5}$ & 0.12 \\
\hline $\begin{array}{l}\text { Hormone } \\
\text { GWAS }\end{array}$ & $\begin{array}{l}\text { Affected } \\
\text { hormone }\end{array}$ & & & & & & & & & & \\
\hline rs4784336 & SHBG & Dicamba & $\begin{array}{c}A A \\
A C+C C\end{array}$ & $\begin{array}{c}258 / 473 \\
66 / 98\end{array}$ & $\begin{array}{l}1.0 \\
1.0\end{array}$ & $\begin{array}{c}130 / 273 \\
42 / 87\end{array}$ & $\begin{array}{l}0.87(0.65,1.15) \\
0.65(0.39,1.08)\end{array}$ & $\begin{array}{c}152 / 274 \\
24 / 87\end{array}$ & $\begin{array}{l}1.00(0.76,1.32) \\
0.36(0.20,0.65)\end{array}$ & $3.7 \times 10^{-3}$ & 0.90 \\
\hline rs1017993 & DHEAS & Alachlor & $\begin{array}{c}\mathrm{CC} \\
\mathrm{CT}+\pi\end{array}$ & $\begin{array}{l}182 / 406 \\
95 / 140\end{array}$ & $\begin{array}{l}1.0 \\
1.0\end{array}$ & $\begin{array}{c}135 / 282 \\
65 / 106\end{array}$ & $\begin{array}{l}1.07(0.81,1.41) \\
0.92(0.61,1.40)\end{array}$ & $\begin{array}{l}147 / 273 \\
47 / 113\end{array}$ & $\begin{array}{l}1.21(0.92,1.58) \\
0.60(0.39,0.93)\end{array}$ & $9.2 \times 10^{-3}$ & 1.00 \\
\hline
\end{tabular}

ORs adjusted for age and state.

aStrata with less than five observations per cell or qualitative interactions excluded. Interactions that were statistically significant (p-int < 0.01$)$ and for which there was a significant association between the pesticide and SNP ( $p$ < 0.05) with a monotonic pattern in at least one genotype stratum are included in table.

${ }^{b}$ The $q$-value adjusts the $p$-value for multiple statistical comparisons using the false discovery rate (FDR) method.

\section{DISCUSSION}

In this case-control study nested within the AHS cohort, we evaluated evidence of statistical interaction between pesticide exposure and SNPs in genes involved in steroid hormone signaling, metabolism, or regulation with the risk of prostate cancer. We observed several notable interactions which help to generate additional hypotheses as to how pesticides may interact with genetic variation in hormone-related genes to affect prostate cancer risk.

The interaction between dicamba and rs8192166 in SRD5A1 and risk of prostate cancer remained significant after correction for multiple testing. We observed an inverse association between exposure to dicamba and prostate cancer risk among those carrying the homozygous wild-type genotype at a locus in this important hormone metabolism and regulatory gene. $S R D 5 A 1$ is one of the three steroid reductase $5 \mathrm{~A}$ isoforms and is known to play a role in the bioconversion of testosterone to the more biologically active dihydrotestosterone (DHT) in the prostate gland ( $S R D 5 A 1$ is highly expressed in prostate tissues) (39-41). DHT is involved in the transcription of androgen-response elements in the genome and facilitates cell proliferation and aspects of cell cycle control which may be aberrant in cancer cells. Dicamba has been shown to interact with hormone homeostasis in non-mammalian experimental systems at environmentally relevant levels (42). Among those 
TABLE 5 | Interactions between insecticides and SNPs in hormonal candidate pathway with prostate cancer risk ( $p<0.01)$.

\begin{tabular}{|c|c|c|c|c|c|c|c|c|c|c|c|}
\hline \multirow[b]{2}{*}{ SNPa } & \multirow[b]{2}{*}{ Tagged gene } & \multirow[b]{2}{*}{ Pesticide } & \multirow[b]{2}{*}{ Genotype } & \multicolumn{2}{|c|}{ None } & \multicolumn{2}{|c|}{ Low exposure } & \multicolumn{2}{|c|}{ High exposure } & \multirow[b]{2}{*}{$p$-int ${ }^{b}$} & \multirow[b]{2}{*}{$q$-value ${ }^{c}$} \\
\hline & & & & $\mathrm{Ca} / \mathrm{Co}$ & REF & $\mathrm{Ca} / \mathrm{Co}$ & OR (95\% Cl) & $\mathrm{Ca} / \mathrm{Co}$ & OR (95\% Cl) & & \\
\hline \multirow[t]{2}{*}{ rs384346 } & HSD17B4 & Malathion & $\mathrm{AA}$ & $150 / 308$ & 1.0 & $114 / 229$ & $1.04(0.77,1.40)$ & $118 / 235$ & $1.01(0.75,1.36)$ & $2.0 \times 10^{-3}$ & 0.16 \\
\hline & & & $A T+T$ & $75 / 88$ & 1.0 & $48 / 98$ & $0.58(0.36,0.92)$ & $34 / 93$ & $0.43(0.26,0.71)$ & & \\
\hline \multirow[t]{2}{*}{ rs384346 } & HSD17B4 & Carbaryl & $\mathrm{AA}$ & $241 / 466$ & 1.0 & 79/162 & $0.91(0.67,1.25)$ & $88 / 177$ & $0.78(0.55,1.12)$ & $2.8 \times 10^{-3}$ & 0.16 \\
\hline & & & $A T+\Pi T$ & $111 / 164$ & 1.0 & $36 / 75$ & $0.68(0.42,1.09)$ & $14 / 62$ & $0.27(0.13,0.55)$ & & \\
\hline \multirow[t]{2}{*}{ rs7723390 } & HSD17B4 & Terbufos & $\pi$ & $335 / 644$ & 1.0 & $112 / 197$ & $1.11(0.85,1.46)$ & $94 / 209$ & $0.91(0.69,1.21)$ & $2.1 \times 10^{-3}$ & 0.16 \\
\hline & & & $\mathrm{CT}+\mathrm{CC}$ & $50 / 121$ & 1.0 & $25 / 37$ & $1.58(0.85,2.95)$ & 32/32 & $2.47(1.36,4.51)$ & & \\
\hline \multirow[t]{2}{*}{ rs7723390 } & HSD17B4 & Fonofos & $\pi$ & $418 / 796$ & 1.0 & $68 / 129$ & $1.04(0.75,1.44)$ & $62 / 127$ & $0.96(0.69,1.34)$ & $5.5 \times 10^{-3}$ & 0.20 \\
\hline & & & $\mathrm{CT}+\mathrm{CC}$ & $67 / 147$ & 1.0 & $15 / 23$ & $1.40(0.68,2.89)$ & $25 / 21$ & $2.51(1.29,4.90)$ & & \\
\hline
\end{tabular}

ORs adjusted for age and state.

${ }^{a}$ Pesticide-SNP interaction significant after false discovery rate adjustment. No pesticide-SNP interaction statistically significant after global FDR analysis.

${ }^{b}$ Strata with less than five observations per cell or qualitative interactions excluded. Interactions that were statistically significant (p-int < 0.01$)$ and for which there was a significant association between the pesticide and SNP $(p<0.05)$ with a monotonic pattern in at least one genotype stratum are included in table.

${ }^{c}$ The $q$-value adjusts the $p$-value for multiple statistical comparisons using the false discovery rate (FDR) method.

with the homozygous wild-type genotype at rs8192166 in gene SRD5A1, dicamba may interact with the metabolic conversion to the more biologically potent androgen DHT, in turn potentially influencing or reducing the conversion of testosterone to DHT in the prostate. If so, decreased concentration of bioactive androgen in the prostate may reduce cell proliferation, thus reducing prostate cancer risk; however, there are no data to support this assertion. It may, however, help to explain previously observed risk estimates at and below unity for the association between this pesticide and prostate cancer in the larger AHS cohort (4).

We also observed evidence of a modifying role of SNPs that were previously associated with circulating hormone concentrations in GWAS, as well as several different statistical interactions between insecticides and two SNPs in the HSD17B4 gene. These statistical interactions were not robust to multiple comparisons. Interestingly, we observed evidence of an apparent inverse association with prostate cancer with use of several pesticides in the presence of certain SNPs. There is evidence in the literature that shows an inverse association between some putative endocrine disrupting chemicals and hormonal cancers, although the mechanism by which these might decrease disease development is unclear. A small number of laboratory studies have tested members of the organophosphate and carbamate class of pesticides including carbaryl and reported significant inhibition of the metabolism of estradiol and testosterone in the presence of these pesticides $(14,17,18,43-45)$. Other studies in humans have shown a significantly reduced risk of testicular cancer (46) and a reduced risk of metastatic prostate cancer (47) associated with polychlorinated biphenyl exposure, known endocrine disrupting chemicals. Thus, a role for hormonal perturbation is plausible.

In our study, two organophosphate insecticides, terbufos and fonofos, were associated with an increased risk of prostate cancer among those carrying one or two copies of the variant allele in HSD17B4 (rs7723390), which showed a low correlation with rs384346, and no association among men carrying two copies of the wild-type allele. Although there is a known role for HSD17B4 in estradiol metabolism, laboratory studies have illustrated reduced metabolism of testosterone in the presence of fonofos (terbufos not tested) (18). Over the past decades, epidemiologic studies have suggested that the combined action of androgens and estrogens may play a role in prostate carcinogenesis and specifically in the development of aggressive prostate cancer (24, $41,48)$. Notably, in the AHS, both terbufos and fonofos have been associated with the risk of aggressive prostate cancer (4). Thus, the observed increases and decreases in risk of prostate cancer for the insecticides in Table 4, which vary by HSD17B4 SNP, may be explained by this complex balance of androgens and estrogens which have been shown to effect prostate cancer development.

There are several strengths and limitations to note. The potential for information bias is low in this study for several important reasons. Lifetime use of pesticides among this occupational cohort is measured with high validity and reliability $(49,50)$. Furthermore, given the quality of the exposure data and the large sample size, we were able to perform analyses at the individual pesticide level and not merely classes of chemical. There are likely few true confounding factors in the relation between genetic variability and disease. We were able to evaluate SNPs among hormone signaling, metabolism, and regulatory genes in this analysis comprehensively and used two methods to identify SNPs for inclusion into our study, i.e., tagging SNPs in candidate hormone pathway genes and GWAS identified SNPs. However, we were limited to the tagging SNPs for genes included in a group genotyping platform. We performed many different statistical tests in this evaluation, increasing the potential of identifying false-positive associations. However, we adjusted for this possibility using FDR methods. Despite the large sample size, we were still limited by the relatively small numbers of participants carrying the variant allele for rare SNPs, as well as small numbers for less frequently used pesticides such as fumigants or fungicides. Furthermore, we were underpowered to investigate whether there were notable interactions for aggressive prostate cancer (aggressive cases, $n=346$ ), although much of the results presented were consistent if we only considered this subgroup of cases (Table S3 in Supplementary Material). Additionally, the AHS study participants included in this study are all white and occupationally exposed to pesticides, limiting the generalizability of our study 
results to the general population. However, our restriction to white men also limited the potential for population stratification to influence our findings.

High prior interest still remains in the hormonal pathway and its influence on prostate cancer initiation and progression, as well as the possible role of pesticides to disrupt this and other endocrine regulatory pathways. Future work should continue to consider newly identified SNPs that may affect circulating hormone concentrations, and further evaluation of risk of aggressive prostate cancer as cases accrue in this cohort. There is also a need for continued laboratory analyses to investigate the possible biological mechanisms through which pesticides may influence hormone synthesis, metabolism or regulation, and ultimately prostate cancer risk.

\section{ETHICS STATEMENT}

The study was carried out in accordance with the recommendations of U.S. National Cancer Institute Special Studies IRB, the Westat Institutional Review Board, and the University of Iowa Institutional Review Board.

\section{REFERENCES}

1. Keller-Byrne JE, Khuder SA, Schaub EA. Meta-analyses of prostate cancer and farming. Am J Ind Med (1997) 31:580-6. doi:10.1002/ (SICI) 1097-0274(199705)31:5<580::AID-AJIM13>3.3.CO;2-V

2. Koutros S, Alavanja MC, Lubin JH, Sandler DP, Hoppin JA, Lynch CF, et al. An update of cancer incidence in the Agricultural Health Study. J Occup Environ Med (2010) 52:1098-105. doi:10.1097/JOM.0b013e3181f72b7c

3. Van Maele-Fabry G, Willems JL. Prostate cancer among pesticide applicators: a meta-analysis. Int Arch Occup Environ Health (2004) 77:559-70. doi:10.1007/ s00420-004-0548-8

4. Koutros S, Beane Freeman LE, Lubin JH, Heltshe SL, Andreotti G, Barry KH, et al. Risk of total and aggressive prostate cancer and pesticide use in the Agricultural Health Study. Am J Epidemiol (2013) 177:59-74. doi:10.1093/aje/ kws225

5. Andreotti G, Koutros S, Berndt SI, Hughes Barry K, Hou L, Hoppin JA, et al. The interaction between pesticide use and genetic variants involved in lipid metabolism on prostate cancer risk. J Cancer Epidemiol (2012) 2012:358076. doi:10.1155/2012/358076

6. Barry KH, Koutros S, Andreotti G, Sandler DP, Burdette LA, Yeager M, et al. Genetic variation in nucleotide excision repair pathway genes, pesticide exposure and prostate cancer risk. Carcinogenesis (2012) 33:331-7. doi:10.1093/ carcin/bgr258

7. Barry KH, Koutros S, Berndt SI, Andreotti G, Hoppin JA, Sandler DP, et al. Genetic variation in base excision repair pathway genes, pesticide exposure, and prostate cancer risk. Environ Health Perspect (2011) 119:1726-32. doi:10.1289/ehp.1103454

8. Karami S, Andreotti G, Koutros S, Barry KH, Moore LE, Han S, et al. Pesticide exposure and inherited variants in vitamin d pathway genes in relation to prostate cancer. Cancer Epidemiol Biomarkers Prev (2013) 22:1557-66. doi:10.1158/1055-9965.EPI-12-1454

9. Koutros S, Andreotti G, Berndt SI, Hughes Barry K, Lubin JH, Hoppin JA, et al. Xenobiotic-metabolizing gene variants, pesticide use, and the risk of prostate cancer. Pharmacogenet Genomics (2011) 21:615-23. doi:10.1097/ FPC.0b013e3283493a57

10. Moore RA. Endocrinology of Neoplastic Disease. New York: Oxford University Press (1947).

11. Noble RL. The development of prostatic adenocarcinoma in $\mathrm{Nb}$ rats following prolonged sex hormone administration. Cancer Res (1977) 37: 1929-33.

12. Wilson JD, Roehrborn C. Long-term consequences of castration in men: lessons from the Skoptzy and the eunuchs of the Chinese and Ottoman

\section{AUTHOR CONTRIBUTIONS}

$\mathrm{CC}, \mathrm{KB}, \mathrm{LF}, \mathrm{SB}$, and SK contributed to the design, execution, and analysis of this paper. $\mathrm{CC}, \mathrm{KB}$, and SK drafted the manuscript. LB and MY were responsible for the genotyping performed. All the authors (including MC, SPK, GA, and MA) were involved in the critical revision of the manuscript.

\section{ACKNOWLEDGMENTS}

We thank the participants in the Agricultural Health Study for their contributions in support of this research. This work was supported by the Intramural Research Program of the National Institutes of Health, NCI, Division of Cancer Epidemiology and Genetics (Z01CP010119).

\section{SUPPLEMENTARY MATERIAL}

The Supplementary Material for this article can be found online at http://journal.frontiersin.org/article/10.3389/fonc.2016.00237/ full\#supplementary-material.

courts. JClin Endocrinol Metab (1999) 84:4324-31. doi:10.1210/jcem.84. 12.6206

13. Andersen HR, Vinggaard AM, Rasmussen TH, Gjermandsen IM, BonefeldJørgensen EC. Effects of currently used pesticides in assays for estrogenicity, androgenicity, and aromatase activity in vitro. Toxicol Appl Pharmacol (2002) 179:1-12. doi:10.1006/taap.2001.9347

14. Curtis LR. Organophosphate antagonism of the androgen receptor. Toxicol Sci (2001) 60:1-2. doi:10.1093/toxsci/60.1.1

15. Henderson BE, Feigelson HS. Hormonal carcinogenesis. Carcinogenesis (2000) 21:427-33. doi:10.1093/carcin/21.3.427

16. Tamura H, Maness SC, Reischmann K, Dorman DC, Gray LE, Gaido KW. Androgen receptor antagonism by the organophosphate insecticide fenitrothion. Toxicol Sci (2001) 60:56-62. doi:10.1093/toxsci/60.1.56

17. Usmani KA, Cho TM, Rose RL, Hodgson E. Inhibition of the human liver microsomal and human cytochrome P450 1A2 and 3A4 metabolism of estradiol by deployment-related and other chemicals. Drug Metab Dispos (2006) 34:1606-14. doi:10.1124/dmd.106.010439

18. Usmani KA, Rose RL, Hodgson E. Inhibition and activation of the human liver microsomal and human cytochrome P450 3A4 metabolism of testosterone by deployment-related chemicals. Drug Metab Dispos (2003) 31:384-91. doi:10.1124/dmd.31.4.384

19. Alavanja MC, Sandler DP, McMaster SB, Zahm SH, McDonnell CJ, Lynch CF, et al. The Agricultural Health Study. Environ Health Perspect (1996) 104:362-9 doi:10.1289/ehp.96104362

20. Tarone RE, Alavanja MC, Zahm SH, Lubin JH, Sandler DP, McMaster SB, et al. The Agricultural Health Study: factors affecting completion and return of self-administered questionnaires in a large prospective cohort study of pesticide applicators. Am J Ind Med (1997) 31:233-42. doi:10.1002/ (SICI)1097-0274(199702)31:2<233::AID-AJIM13>3.3.CO;2-B

21. Alavanja MC, Sandler DP, McDonnell CJ, Lynch CF, Pennybacker M, Zahm SH, et al. Characteristics of pesticide use in a pesticide applicator cohort: the Agricultural Health Study. Environ Res (1999) 80:172-9. doi:10.1006/enrs.1998.3887

22. Coble J, Arbuckle T, Lee W, Alavanja M, Dosemeci M. The validation of a pesticide exposure algorithm using biological monitoring results. J Occup Environ Hyg (2005) 2:194-201. doi:10.1080/15459620590923343

23. Coble J, Thomas KW, Hines CJ, Hoppin JA, Dosemeci M, Curwin B, et al. An updated algorithm for estimation of pesticide exposure intensity in the Agricultural Health Study. Int J Environ Res Public Health (2011) 8:4608-22. doi:10.3390/ijerph8124608

24. Black A, Pinsky PF, Grubb RL III, Falk RT, Hsing AW, Chu L, et al. Sex steroid hormone metabolism in relation to risk of aggressive prostate cancer. Cancer 
Epidemiol Biomarkers Prev (2014) 23:2374-82. doi:10.1158/1055-9965. EPI-14-0700

25. Hyland PL, Freedman ND, Hu N, Tang ZZ, Wang L, Wang C, et al. Genetic variants in sex hormone metabolic pathway genes and risk of esophageal squamous cell carcinoma. Carcinogenesis (2013) 34:1062-8. doi:10.1093/ carcin/bgt030

26. Parnes HL, Thompson IM, Ford LG. Prevention of hormone-related cancers: prostate cancer. JClin Oncol (2005) 23:368-77. doi:10.1200/JCO.2005. 08.027

27. Yang HP, Gonzalez Bosquet J, Li Q, Platz EA, Brinton LA, Sherman ME, et al. Common genetic variation in the sex hormone metabolic pathway and endometrial cancer risk: pathway-based evaluation of candidate genes. Carcinogenesis (2010) 31:827-33. doi:10.1093/carcin/bgp328

28. Coviello AD, Haring R, Wellons M, Vaidya D, Lehtimäki T, Keildson S, et al. A genome-wide association meta-analysis of circulating sex hormone-binding globulin reveals multiple loci implicated in sex steroid hormone regulation. PLoS Genet (2012) 8:e1002805. doi:10.1371/journal.pgen. 1002805

29. Jin G, Sun J, Kim ST, Feng J, Wang Z, Tao S, et al. Genome-wide association study identifies a new locus JMJD1C at 10q21 that may influence serum androgen levels in men. Hum Mol Genet (2012) 21:5222-8. doi:10.1093/hmg/ dds 361

30. Ohlsson C, Wallaschofski H, Lunetta KL, Stolk L, Perry JR, Koster A, et al. Genetic determinants of serum testosterone concentrations in men. PLoS Genet (2011) 7:e1002313. doi:10.1371/journal.pgen.1002313

31. Prescott J, Thompson DJ, Kraft P, Chanock SJ, Audley T, Brown J, et al. Genome-wide association study of circulating estradiol, testosterone, and sex hormone-binding globulin in postmenopausal women. PLoS One (2012) 7:e37815. doi:10.1371/journal.pone.0037815

32. Zhai G, Teumer A, Stolk L, Perry JR, Vandenput L, Coviello AD, et al. Eight common genetic variants associated with serum DHEAS levels suggest a key role in ageing mechanisms. PLoS Genet (2011) 7:e1002025. doi:10.1371/ journal.pgen.1002025

33. Johnson AD, Handsaker RE, Pulit SL, Nizzari MM, O’Donnell CJ, de Bakker PI. SNAP: a web-based tool for identification and annotation of proxy SNPs using HapMap. Bioinformatics (2008) 24:2938-9. doi:10.1093/bioinformatics/ btn564

34. Purcell S, Neale B, Todd-Brown K, Thomas L, Ferreira MA, Bender D, et al. PLINK: a tool set for whole-genome association and population-based linkage analyses. Am J Hum Genet (2007) 81:559-75. doi:10.1086/519795

35. Benjamini $Y$, Hochberg Y. Controlling the false discovery rate: a practical and powerful approach to multiple testing. J R Stat Soc Series B Stat Methodol (1995) 57:289-300.

36. Koutros S, Beane Freeman LE, Berndt SI, Andreotti G, Lubin JH, Sandler DP, et al. Pesticide use modifies the association between genetic variants on chromosome 8q24 and prostate cancer. Cancer Res (2010) 70:9224-33. doi:10.1158/0008-5472.CAN-10-1078

37. Porcu E, Medici M, Pistis G, Volpato CB, Wilson SG, Cappola AR, et al. A meta-analysis of thyroid-related traits reveals novel loci and genderspecific differences in the regulation of thyroid function. PLoS Genet (2013) 9:e1003266. doi:10.1371/journal.pgen.1003266

38. Hwang S-J, Yang Q, Meigs JB, Pearce EN, Fox CS. A genome-wide association for kidney function and endocrine-related traits in the NHLBI's Framingham Heart Study. BMC Med Genet (2007) 8(Suppl 1):S10. doi:10.1186/1471-23508-S1-S10

39. Eaton NE, Reeves GK, Appleby PN, Key TJ. Endogenous sex hormones and prostate cancer: a quantitative review of prospective studies. Br J Cancer (1999) 80:930-4. doi:10.1038/sj.bjc.6690445
40. Parsons JK, Carter HB, Platz EA, Wright EJ, Landis P, Metter EJ. Serum testosterone and the risk of prostate cancer: potential implications for testosterone therapy. Cancer Epidemiol Biomarkers Prev (2005) 14:2257-60. doi:10.1158/1055-9965.EPI-04-0715

41. Platz EA, Giovannucci E. The epidemiology of sex steroid hormones and their signaling and metabolic pathways in the etiology of prostate cancer. J Steroid Biochem Mol Biol (2004) 92:237-53. doi:10.1016/j.jsbmb.2004. 10.002

42. Zhu L, Li W, Zha J, Wang Z. Dicamba affects sex steroid hormone level and mRNA expression of related genes in adult rare minnow (Gobiocypris rarus) at environmentally relevant concentrations. Environ Toxicol (2015) 30:693-703. doi:10.1002/tox.21947

43. Hodgson E, Rose RL. Human metabolism and metabolic interactions of deployment-related chemicals. Drug Metab Rev (2005) 37:1-39. doi:10.1081/ DMR-200046955

44. Hodgson E, Rose RL. Organophosphorus chemicals: potent inhibitors of the human metabolism of steroid hormones and xenobiotics. Drug Metab Rev (2006) 38:149-62. doi:10.1080/03602530600569984

45. Venerosi A, Ricceri L, Tait S, Calamandrei G. Sex dimorphic behaviors as markers of neuroendocrine disruption by environmental chemicals: the case of chlorpyrifos. Neurotoxicology (2012) 33:1420-6. doi:10.1016/j. neuro.2012.08.009

46. Chia VM, Li Y, Quraishi SM, Graubard BI, Figueroa JD, Weber JP, et al. Effect modification of endocrine disruptors and testicular germ cell tumour risk by hormone-metabolizing genes. Int J Androl (2010) 33:588-96. doi:10.1111/j.1365-2605.2009.00975.x

47. Koutros S, Langseth H, Grimsrud TK, Barr DB, Vermeulen R, Portengen $\mathrm{L}$, et al. Prediagnostic serum organochlorine concentrations and metastatic prostate cancer: a Nested Case-Control Study in the Norwegian Janus Serum Bank Cohort. Environ Health Perspect (2015) 123:867-72. doi:10.1289/ ehp. 1408245

48. Gann PH, Hennekens CH, Ma J, Longcope C, Stampfer MJ. Prospective study of sex hormone levels and risk of prostate cancer. J Natl Cancer Inst (1996) 88:1118-26. doi:10.1093/jnci/88.16.1118

49. Blair A, Tarone R, Sandler D, Lynch C, Rowland A, Wintersteen W, et al. Reliability of reporting on lifestyle and agricultural factors by a sample of participants in the Agricultural Health Study from Iowa. Ann Epidemiol (2000) 10:478. doi:10.1016/S1047-2797(00)00113-7

50. Hoppin JA, Yucel F, Dosemeci M, Sandler DP. Accuracy of self-reported pesticide use duration information from licensed pesticide applicators in the Agricultural Health Study. J Expo Anal Environ Epidemiol (2002) 12:313-8. doi:10.1038/sj.jea.7500232

Disclaimer: Although the author is a FDA/CTP employee, this work was not done as part his/her official duties. This publication/presentation reflects the views of the author and should not be construed to reflect the FDA/CTP's views or policies.

Conflict of Interest Statement: The authors declare that the research was conducted in the absence of any commercial or financial relationships that could be construed as a potential conflict of interest.

Copyright (๔) 2016 Christensen, Barry, Andreotti, Alavanja, Cook, Kelly, Burdett, Yeager, Beane Freeman, Berndt and Koutros. This is an open-access article distributed under the terms of the Creative Commons Attribution License (CC BY). The use, distribution or reproduction in other forums is permitted, provided the original author(s) or licensor are credited and that the original publication in this journal is cited, in accordance with accepted academic practice. No use, distribution or reproduction is permitted which does not comply with these terms. 